\title{
ĐÁNH GIÁ KẾT QUẢ CAN THIỆP NỘI MẠCH ĐIỀU TRI TẮC ĐỘNG MẠCH MẠN TÍNH DƯớI GỐI
}

Lâm Văn Nút*, Phạm Minh Ánh", Lê Đức Tín", Võ Thị Ngọc Mỹ ${ }^{*}$,Huỳnh Thị Minh Thu*

\section{TÓM TÁ̀T}

Mẫu nghiên cứu có 101 bệnh nhân. Trong đó, tỷ lệ nữ chiếm $52.5 \%$, tuổi trung bình $75.5 \pm 11.4$. Triệu chứng chính của bệnh nhân là đau, chiếm $59.4 \%$, thiếu máu chi nghiêm trọng $87.1 \%$, loét hoặc hoại tử đầu chi $51.2 \%$. Tạo hình lòng mạch máu bằng nong bóng chiếm $78.2 \%$, kết hợp đặt giá đỡ nội mạch chiếm $21.8 \%$. Can thiệp tầng dưới gối đơn thuần chiếm $34.7 \%$, tầng dưới gối phối hợp đùi khoeo trên và dưới gối chiếm $57.4 \%$. Thời gian can thiệp $127 \pm 40.8$ phút. Thời gian nằm viện trung bình là $4 \pm 3.1$ ngày. Biến chứng chung chiếm $14.9 \%$ trong đó biến chứng tắc mạch $3.96 \%$, tụ máu $3 \%$, cắt cụt $5.94 \%$ và một trường hợp tử vong. Phương pháp can thiệp nội mạch thành công về kỹ thuật và sau 1 tháng là $86.2 \%$, tỉ lệ thành công sau 3 tháng, 12 tháng lần lượt là $80.2 \%$ và $53.7 \%$. Phương pháp can thiệp nội mạch điều trị tắc động mạch mạn tính dưới gối là phương pháp ít xâm lấn nên an toàn, hiệu quả, thời gian nằm viện ngắn và bệnh nhân hồi phục nhanh. Tỷ lệ thành công sau can thiệp là $86,2 \%$, sau 12 tháng $53,7 \%$.

Từ khóa: Tắc mạch dưới gối, can thiệp nôi mạch, bệnh mạch máu ngoại biên

\section{SUMMARY}

\section{EVALUATION OF ENDOVASCULAR INTERVENTION THERAPY RESULTS IN CHRONIC BELOW-THE-KNEE (BTK) ARTERIAL OCCLUSIVE DISEASE}

The study sample of 101 patients. We had counted $52.5 \%$ female rates, average ages $75.5 \pm$ 11.4. Chief complain symptom was a painfully, $59.4 \%$ sample, critical limb ischemia had got $87.1 \%$, ulcer or gangrange was $51.2 \%$ smaple.
Percutaneous transluminal angioplasty (PTA) performed by $78.2 \%$, PTA and stent replacement combination accounted for $21.8 \%$. BTK intervention simple accounted for $34.7 \%$, Femoropopliteal combination was $57.4 \%$. The procedure times had $127 \pm 40.8$ minutes. The time of hospitalization average was $4 \pm 3.1$ days. Total complication was $14.9 \%$ thrombosis was $3.96 \%$, hematoma 3\%, amputation $5.94 \%$ and mortality rate had got 1 case in our research. Technique and 1 month results success rates were $86.2 \%, 12$ months results were $53.7 \%$. The intervention endovascular therapy of chronic arterial occlusion of the lower extremity less invasive method which is safe, effective, shorter hospital stays and faster recovery of patients. 1 month results achieve a high success rate, however the results 12 months were $53.7 \%$.

Key words: Below-The-Knee (BTK) Arterial occlusive Disease, endovascular intervention, peripheral artery disease.

\section{I. ĐẶT VẤN ĐỀ}

Tắc động mạch mạn tính chi dưới là bệnh lý thường gặp, bệnh thường diễn tiến âm thầm và không triệu chứng nên khi bệnh nhân đến khám và điều trị thường là ở giai đoạn muộn. Do đó việc điều trị bệnh tắc động mạch chi dưới, đặc biệt tắc động mạch dưới gối thật sự là thách thức đối với phẫu thuật viên mạch máu. Theo thống kê, hiện nay ở Châu Âu và Bắc Mỹ có khoảng 27 triệu người bị mắc bệnh này. Tại Mỹ, theo nghiên

* Khoa Phẫu thuật Mạch máu, BV Chợ Rẫy TPHCM Người chịu trách nhiệm khoa học: Ts. Lâm Văn Nút Ngày nhận bài: 01/05/2018 - Ngày Cho Phép Đăng: 20/05/2018

Phản Biện Khoa học: GS.TS. Bùi Đúc Phú PGS.TS. Đặng Ngọc Hùng 
cứu của John W. York và Spence M. Taylor (2010) [10], hàng năm có hơn 10 triệu người mắc bệnh tắc động mạch chi dưới, trong đó bệnh nhân trên 70 tuổi chiếm tỉ lệ $14,5 \%$. Mỗi năm có trên 100.000 bệnh nhân cần phải điều trị tái lưu thông mạch máu, trong đó cắt cụt chi chiếm tỉ lệ từ 1 đến $7 \%$ trong tất cả các trường hợp.

Tại bệnh viện Chợ Rẫy, năm 2012, khoa Phẫu thuật Mạch máu của chúng tôi đã bước đầu điều trị bệnh nhân tắc động mạch mãn chi dưới bằng can thiệp nội mạch: Nong tạo hình lòng mạch qua da (PTA: percutaneous transluminal angioplasty), đặt giá đỡ nội mạch (Stent) bước đầu cho kết quả khả quan. Số lượng bệnh nhân tắc động mạch mãn tính chi dưới đến điều trị bằng kỹ thuật này ngày càng tăng, từ 39 trường hợp năm 2013 tăng đến 265 trường hợp năm 2017. Tuy nhiên, hiện nay tại nước ta vẫn còn ít công trình nghiên cứu về hiệu quả kỹ thuật can thiệp nội mạch dưới gối. Do đó, mục tiêu đề tài nghiên cứu của chúng tôi là: Đánh giá kết quả can thiệp nội mạch trong điều trị tắc động mạch mạn tính duới gối.

\section{PHƯƠNG PHÁP NGHIÊN CÚU:}

2.1. Thiết kế nghiên cứu: hồi cứu mô tả.

2.2. Thời gian nghiên cứu: Từ tháng 01 năm 2016 đến tháng 12 năm 2017

2.3. Địa điểm nghiên cứu: Khoa Phẫu thuật mạch máu Bệnh viện Chợ Rẫy.

\section{4. Đối tượng nghiên cứu:[7]}

Tiêu chuẩn chọn mẫu:

Tất cả những trường hợp có bệnh tắc hẹp động mạch mạn tính dưới gối điều trị bằng phương pháp can thiệp nội mạch tại khoa Phẫu thuật Mạch máu, Bệnh viện Chợ Rẫy.

\section{Tiêu chuẩn loại trừ:}

- Phẫu thuật tái thông động mạch đơn thuần (cầu nối).

- Phẫu thuật kết hợp can thiệp nội mạch (hybrid).
- Tắc hẹp các tầng trên gối chưa được tái thông hoặc tái thông không đủ (đường kính lòng mạch sau tái thông các tầng trên gối phải $\geq 70 \%$ lòng mạch).

\section{5. Đánh giá kết quả điều trị:}

- Đánh giá kết quả can thiệp dựa vào: lâm sàng, cận lâm sàng.[9]

\begin{tabular}{|l|c|}
\hline \multicolumn{1}{|c|}{$\begin{array}{c}\text { Lâm sàng (phân loại } \\
\text { Rutherford) }\end{array}$} & Tăng ít nhất 1 độ \\
\hline Siêu âm & $\begin{array}{c}\text { Đường kính tái hẹp } \\
\text { lòng }<70 \%\end{array}$ \\
\hline ABI & Tăng $>0.15$ \\
\hline
\end{tabular}

- Đánh giá kết quả can thiệp tại 2 thời điểm: sau phẫu thuật 01 tháng và 12 tháng.

III. KẾT QUẢ NGHIÊN CỨU: Có 101 trường hợp thỏa tiêu chuẩn chọn bệnh.

\subsection{Tuổi, giới và các yếu tố nguy co', bệnh} kết hợp:

Bảng 3.1. Tuổi, giới và các yếu tố nguy cơ, bệnh phối hợp

\begin{tabular}{|l|c|c|}
\hline & N (\%) & Trung bình \\
\hline Tuổi & $\begin{array}{c}75.5 \pm 11.4 \\
(44-97)\end{array}$ \\
\hline Giới & $\begin{array}{c}\text { Nam: } 48 \\
(47.5)\end{array}$ & $\begin{array}{c}\text { Nũ: } 53 \\
(52.5 \%)\end{array}$ \\
\hline RLCH lipid máu & $69(68.3)$ & \\
\hline Tăng huyết áp & $57(56.4)$ & \\
\hline Hút thuốc lá & $54(53.5)$ & \\
\hline Đái tháo đường & $43(42.6)$ & \\
\hline Bệnh động mạch cảnh & $19(18.8)$ & \\
\hline Tai biến mạch máu não & $10(9.9)$ & \\
\hline Suy thận mạn & $7(6.9)$ & \\
\hline Bệnh mạch vành & $5(5)$ & \\
\hline Suy tim & $4(4)$ & \\
\hline Nhồi máu cơ tim & $2(2)$ & \\
\hline Xơ gan & $0(0)$ & \\
\hline
\end{tabular}




\subsection{Phân loại Rutherford:}

Bảng 3.2. Phân loại theo Rutherford.

\begin{tabular}{|c|c|c|c|}
\hline $\begin{array}{c}\text { Giai } \\
\text { đoạn }\end{array}$ & Độ & $\begin{array}{c}\text { N (\%) trước } \\
\text { can thiệp }\end{array}$ & $\begin{array}{c}\text { N (\%) sau } \\
\text { can thiệp }\end{array}$ \\
\hline 0 & 0 & $0(0)$ & $0(0)$ \\
\hline \multirow{3}{*}{ I } & 1 & $0(0)$ & $5(5.0)$ \\
\cline { 2 - 4 } & 2 & $2(2.0)$ & $5(5.0)$ \\
\cline { 2 - 4 } & 3 & $6(5.9)$ & $18(17.8)$ \\
\hline II & 4 & $15(14.9)$ & $35(34.7)$ \\
\hline III & 5 & $26(25.7)$ & $25(24.8)$ \\
\hline IV & 6 & $52(51.5)$ & $13(12.9)$ \\
\hline Tổng & & $101(100.0)$ & $101(100.0)$ \\
\hline
\end{tabular}

\subsection{Phân loại TASC II:}

Bảng 3.3. Phân loại theo TASC II.

\begin{tabular}{|c|c|}
\hline Giai đoạn & $\mathrm{N}(\%)$ \\
\hline $\mathrm{A}$ & $0(0)$ \\
\hline $\mathrm{B}$ & $2(2.3)$ \\
\hline $\mathrm{C}$ & $33(32.7)$ \\
\hline $\mathrm{D}$ & $65(64.4)$ \\
\hline Tổng & $101(100)$ \\
\hline
\end{tabular}

3.4. Mối liên hệ giữa TASC II với triệu chứng lâm sàng:

Bảng 3.4. Mối liên hệ giữa TASC II với triệu chứng lâm sàng

\begin{tabular}{|c|c|c|}
\hline Biến số & $\begin{array}{c}\text { Đau cách hồi } \\
(\%)\end{array}$ & $\begin{array}{c}\text { Thiếu máu chi } \\
\text { nghiêm trọng }(\%)\end{array}$ \\
\hline A & $0(0)$ & $0(0)$ \\
\hline B & $1(1.0)$ & $2(2.5)$ \\
\hline C & $11(10.9)$ & $22(25.0)$ \\
\hline D & $1(1.0)$ & $64(72.7)$ \\
\hline Tổng (\%) & $13(12.9)$ & $88(87.1)$ \\
\hline
\end{tabular}

\subsection{Chỉ số $A B I$ trước và sau can thiệp:}

Bảng 3.5. Chỉ số $\mathrm{ABI}$ trước và sau can thiệp

\begin{tabular}{|c|c|c|c|}
\hline & Trước & Sau & $\boldsymbol{P}$ \\
\hline ABI & $0.40 \pm 0.05$ & $0.60 \pm 0.03$ & $\mathrm{P}<0.001$ \\
\hline
\end{tabular}

\subsection{Kết quả:}

\subsubsection{Phương pháp vô cảm:}

Bảng 3.6. Phương pháp vô cảm

\begin{tabular}{|l|c|c|}
\hline & $\mathrm{N}$ & $(\%)$ \\
\hline Mê nội khí quản & 5 & 5.0 \\
\hline Gây tê tuỷ sống & 0 & 0 \\
\hline Gây tê tại chỗ & 96 & 95.0 \\
\hline Tồng & 101 & 100.0 \\
\hline
\end{tabular}

\subsection{2. Đường vào can thiệp:}

Bảng 3.7. Đường vào can thiệp

\begin{tabular}{|l|c|c|}
\hline Biến số & $\mathrm{N}$ & $\mathbf{( \% )}$ \\
\hline Xuôi dòng & 101 & 100.0 \\
\hline Ngược dòng & 0 & 0 \\
\hline Tổng & 101 & 100.0 \\
\hline
\end{tabular}

\subsubsection{Sang thương dưới gối:}

Bảng 3.8. Sang thương dưới gối

\begin{tabular}{|c|c|c|c|c|}
\hline & $\begin{array}{c}\text { Thân } \\
\text { chung } \\
\text { chày - } \\
\text { mác }(\%)\end{array}$ & $\begin{array}{c}\text { ĐM } \\
\text { chày } \\
\text { trước } \\
(\%)\end{array}$ & $\begin{array}{c}\text { ĐM } \\
\text { chày } \\
\text { sau }(\%)\end{array}$ & $\begin{array}{c}\text { ĐM } \\
\text { mác } \\
(\%)\end{array}$ \\
\hline Tổng & $34(33.7)$ & $\begin{array}{c}76 \\
(75.2)\end{array}$ & $\begin{array}{c}77 \\
(76.2)\end{array}$ & $\begin{array}{c}46 \\
(45.5)\end{array}$ \\
\hline
\end{tabular}

\subsubsection{Phương pháp can thiệp nội mạch}

Bảng 3.9. Phương pháp can thiệp

\begin{tabular}{|l|c|c|}
\hline Biến số & N & (\%) \\
\hline Nong bóng & 79 & 78.2 \\
\hline Đặt giá đỡ & 0 & 0.0 \\
\hline Nong + đặt giá đỡ & 22 & 21.8 \\
\hline Tổng & 101 & 100.0 \\
\hline
\end{tabular}

\subsubsection{Số chi can thiệp}

Bảng 3.10. Chi can thiệp

\begin{tabular}{|l|c|c|}
\hline Chi can thiệp & $\mathrm{N}$ & $(\%)$ \\
\hline 1 chi & 101 & 100.0 \\
\hline 2 chi & 0 & 0 \\
\hline Tổng & 101 & 100.0 \\
\hline
\end{tabular}




\subsubsection{Tầng can thiệp}

Bảng 3.11. Tầng can thiệp

\begin{tabular}{|l|c|c|}
\hline Tầng can thiệp & $\mathrm{N}$ & (\%) \\
\hline Tầng dưới gối & 35 & 34.7 \\
\hline Đùi khoeo trên + dưới gối & 58 & 57.4 \\
\hline Chậu + dưới gối & 3 & 3.0 \\
\hline Chậu đùi khoeo + dưới gối & 5 & 5.0 \\
\hline Tổng & 101 & 100.0 \\
\hline
\end{tabular}

\subsubsection{Thời gian nằm viện}

Bảng 3.12. Thời gian can thiệp, thời gian nằm viện

\begin{tabular}{|l|c|}
\hline Thời gian & Trung bình \\
\hline Thời gian can thiệp (phút) & $127 \pm 40.8(45-260)$ \\
\hline Thời gian nằm viện (ngày) & $4 \pm 3.1(1-18)$ \\
\hline
\end{tabular}

\subsubsection{Biến chứng sau can thiệp}

Bảng 3.13. Biến chứng sau can thiệp

\begin{tabular}{|l|c|c|}
\hline Biến số & $\mathbf{N}$ & $\mathbf{( \% )}$ \\
\hline Tắc mạch & 4 & 3.9 \\
\hline Tụ máu & 3 & 3.0 \\
\hline Nhồi máu cơ tim & 0 & 0 \\
\hline Cắt cụt & 6 & 5.9 \\
\hline Tử vong & 1 & 1.0 \\
\hline Dò động mạch & 0 & 0 \\
\hline Giả phình & 0 & 0 \\
\hline Thủng & 1 & 1.0 \\
\hline Tổng & 15 & 14.9 \\
\hline
\end{tabular}

\subsubsection{Kết quả can thiệp}

Bảng 3.14. Kết quả can thiệp

\begin{tabular}{|l|c|c|}
\hline \multicolumn{1}{|c|}{ Kết quả } & $\begin{array}{c}\text { Thành công } \\
(\%)\end{array}$ & $\begin{array}{c}\text { Thất bại } \\
(\%)\end{array}$ \\
\hline Sau can thiệp $(\mathrm{n}=101)$ & $87(86.2)$ & $14(13.9)$ \\
\hline 3 tháng sau $(\mathrm{n}=101)$ & $81(80.2)$ & $20(19.8)$ \\
\hline 12 tháng sau $(\mathrm{n}=67)$ & $36(53.7)$ & $31(46.3)$ \\
\hline
\end{tabular}

Theo dõi 12 tháng chúng tôi có 13 trường hợp cắt cụt, trong đó cắt cụt $1 / 3$ trên cẳng chân và $1 / 3$ dưới đùi có 6 trường hợp, cắt cụt dưới cổ chân như tháo ngón hoại tử hoặc cắt $1 / 2$ bàn chân có 7 trường hợp.

\section{BÀN LUẬN}

Trong nghiên cứu, tỉ lệ nam và nữ không khác biệt đáng kể với tuổi trung bình 75.5 tuổi, tuổi nhỏ nhất 44 và lớn nhất 97 . Hút thuốc lá 54 trường hợp $(53.5 \%)$, rối loạn chuyển hóa lipid máu 69 trường hợp (68.3\%), tăng huyết áp 57 trường hợp $(56.4 \%)$, đái tháo đường 43 trường hợp (42.6\%) chiếm tỉ lệ khá cao. Theo các tài liệu khác[8], [9], hút thuốc lá và rối loạn chuyển hoá lipid máu trở thành yếu tố thúc đẩy quá trình bệnh lý thành mạch máu, làm tăng độ nặng của bệnh và ảnh hưởng không nhỏ đến bệnh tắc động mạch mạn tính chi dưới.

Triệu chứng chính khiến bệnh nhân nhập viện là đau, chiếm 59.4\% với biểu hiện lâm sàng nặng, ghi nhận hầu hết các trường hợp có phân độ 5,6 theo Rutherford, chiếm tới 77.2\%. Trong đó, có 52 trường hợp chiếm $51.5 \%$ có biểu hiện loét hoặc hoại tử chi. Trên chụp cắt lớp điện toán có dựng hình mạch máu(CTA), tổng thương TASC II $\mathrm{C}$ và $\mathrm{D}$ chiếm lần lượt $32.7 \%$ và $64.4 \%$. Theo khuyến cáo lần 2 cập nhật của TASC (TransAtlantic Inter-Society Consensus) những tổn thương TASC II C có thể phẫu thuật hoặc can thiệp, còn những tổn thương TASC II D nên phẫu thuật[6]. Tuy nhiên nhóm bệnh nhân này đa số đều lớn tuổi, kết hợp nhiều bệnh nội khoa nặng, có nguy cơ cao khi phẫu thuật nên ưu tiên can thiệp, bước đầu cho kết quả tích cực.

Trong quá trình điều trị bệnh nhân tắc động mạch dưới gối chúng tôi nhận thấy động mạch mác là động mạch có tỉ lệ tổn thương (45.5\%) ít hơn động mạch chày trước $(75.2 \%)$ và chày sau (76.2\%).

Phưong pháp vô cảm: Đa số các trường hợp chúng tôi đều gây tê tại chỗ bằng lidocaine $2 \%$ với 96 trường hợp (95\%), chỉ có 5 trường hợp gây mê nội khí quản do bệnh nhân không hợp 
tác trong quá trình can thiệp. Đây là ưu điểm của phương pháp can thiệp nội mạch vì sau can thiệp, bệnh nhân hồi phục nhanh và tránh được biến chứng của gây mê. Điều này rất nặng nề trên những bệnh nhân lớn tuổi, bệnh phối hợp.

Phưong pháp can thiệp: Hầu hết là dùng phương pháp nong bóng, chiếm $78.2 \%$ mẫu nghiên cứu. Nong bóng kết hợp đặt giá đỡ chiếm tỉ lệ thấp, $21.8 \%$ mẫu nghiên cứu. Đặt giá đỡ đơn thuần chúng tôi chưa ghi nhận trường hợp nào. Điều này cho thấy vấn đề đặt giá đỡ không phải là lựa chọn đầu tiên đối với tầng dưới gối. Vì đặc điểm của hệ mạch máu dưới gối là những mạch máu nhỏ, sang thương tắc hẹp kéo dài, lưu lượng thấp nên vấn đề đặt giá đỡ dễ có nguy cơ tái hẹp hoặc tắc sau can thiệp. Tuy nhiên, vì mẫu nghiên cứu còn nhỏ, thiết kế nghiên cứu chưa đủ mạnh nên chúng tôi nghĩ cần phải nghiên cứu kỹ hơn về vấn đề này vì có những bằng chứng cho thấy đặt giá đỡ nội mạch vẫn có hiệu quả [1], [2]. Theo một số tác giả tạo hình bằng bóng phủ thuốc làm giảm đáng kể tỉ lệ tái hẹp cho cả theo dõi ở giai đoạn ngắn hạn và trung hạn []ㅡ, [ㅍ]

Chúng tôi can thiệp chủ yếu là tầng dưới gối phối hợp tầng đùi khoeo chiếm $57.4 \%$. Tất cả các trường hợp chúng tôi can thiệp 1 chi. Thời gian can thiệp trung bình là 127 phút, thời gian nằm viện trung bình 04 ngày.

Biến chứng can thiệp: của chúng tôi có 15 trường hợp chiếm $14.9 \%$. Trong đó có 03 trường hợp tụ máu tại vị trí chọc kim, chúng tôi phải tiến hành phẫu thuật lấy máu tụ; 04 trường hợp tắc mạch sau can thiệp dẫn đến cắt cụt chi, 01 trường hợp tắc mạch, thủng mạch máu và tụ máu vùng cẳng chân phải tiến hành lấy máu tụ và rạch giải áp khoang cẳng chân.

Đánh giá kết quả: Phương pháp can thiệp nội mạch điều trị tắc động mạch dưới gối thành công khi tái tưới máu đạt kết quả cao sau 1 tháng $86.2 \%$, sau 3 tháng $80.2 \%$, sau 12 tháng 53.7\%.
Chúng tôi nhận thấy rằng thời gian can thiệp và thời gian nằm viện trong mẫu nghiên cứu của chúng tôi dài hơn so với các tác giả khác[1], [4]. Phương pháp can thiệp nội mạch đã cải thiện đáng kể các triệu chứng lâm sàng, cận lâm sàng ở giai đoạn ngắn hạn. Đặc biệt là nhóm bệnh nhân lớn tuổi, có bệnh nội khoa nặng, yếu tố nguy cơ cao.

Trong nghiên cứu này chúng tôi nhận thấy đa số bệnh nhân đến bệnh viện điều trị thường ở giai đoạn muộn, theo phân loại Rutherford độ 4,5,6 có 93 trường hợp chiếm tỉ lệ khá lớn $(92.1 \%)$. Tổn thương trên hình ảnh học theo phân loại TASC II ở giai đoạn $\mathrm{C}$ và $\mathrm{D}$ có 98 trường hợp với tỉ lệ $97.1 \%$. Hơn nữa, tổn thương không chỉ riêng tầng dưới gối mà còn tổn thương nhiều tầng khác phối hợp như tầng chậu, tầng đùi - khoeo trên gối. Đều này thật sự là thách thức rất lớn cho chúng tôi trong quá trình can thiệp. Vì những lý do trên có thể giải thích lý do tại sao tỉ lệ thành công của chúng tôi thấp các tác giả khác. Mặt khác, trong số 101 trường hợp can thiệp dưới gối này, chúng tôi cũng chưa sử dụng bóng phủ thuốc cũng như stent phủ thuốc, nên tỉ lệ tái hẹp và tắc lại khá cao trong lô nghiên cứu này, theo dõi sau 1 năm tỉ lệ thành công chỉ còn $53.7 \%$.

Thời gian gần đây, chúng tôi bắt đầu sử dụng bóng phủ thuốc trong can thiệp tắc động mạch mạn tính chi dưới, đặc biệt tắc động mạch dưới gối cho kết quả khả quan. Tuy nhiên, vì số lượng ít và thời gian theo dõi ngắn nên cần thêm thời gian và số trường hợp can thiệp nhiều hơn, khi đó đánh giá kết quả bóng phủ thuốc sẽ có ý nghĩa hơn.

Báo cáo Rosemarie Met và cs (2010), trong 26 trường hợp có tình trạng thiếu máu chi nghiêm trọng do tắc động mạch chày với tổn thương dài được can thiệp nội mạch từ năm 2006 đến 2009, tỉ lệ thành công về kỹ thuật là $88 \%$ và biến chứng có 4 trường hợp. 
Năm 2016, Steiner và cộng sự báo cáo kết quả sử dụng bóng phủ thuốc Lutonix 14 can thiệp điều trị 248 trường hợp tắc động mạch mạn tính dưới gối từ tháng 5 năm 2013 đến tháng 10 năm 2014 tại trung tâm duy nhất. Có 40 bệnh nhân mất dấu trong quá trình theo dõi, còn lại 208 bệnh nhân được theo dõi và phân tích kết quả, trong đó 138 nam, tuổi trung bình 74.1, đau cách hồi chiếm tỉ lệ $38.6 \%$, thiếu máu chi nghiêm trọng $61.4 \%$, tổn thương tắc hoàn toàn $63.6 \%$ và $17.8 \%$ tắc hoàn toàn 3 động mạch dưới gối trước khi can thiệp. Theo dõi thời gian 9 tháng sau can thiệp, tổng cộng có 39 lấn cắt cụt cho 31 chi, trong đó 17 lần lên kế hoạch cắt cựt nhỏ dưới cổ chân, chỉ 9 trường hợp cắt cựt lớn trên gối ( những trường hợp này đều nằm trong nhóm thiếu máu chi cấp tính ). Theo dõi sau 12 tháng có $80 \%$ cải thiện theo phân loại Rutherford từ 2 độ trở lên. Từ đó tác giả kết luận rằng bóng phủ thuốc (Drug Coated Ballons) Lutonix 14 là phương pháp điều trị nhiều hứa hẹn trong điều trị tắc động mạch dưới gối[10].

Thời gian gần đây có nhiều tiến bộ đáng kể trong can thiệp nội mạch như dây dẫn (guide wire) thấm nước nhiều kích cỡ: 0,$035 ; 0,018$; 0,014 inch có thể đi trong lòng động mạch hoặc dưới lớp nội mạc; Catheter trượt hỗ trợ guide wire như Quick cross, seeker...; Dụng cụ cắt nội mạc như Turbohawk, Silverhawk, Jet Stream device sử dụng guide wire 0,014 dùng để cắt nội mạc động mạch đùi và động mạch tầng dưới gối; Bóng hoặc Stent có phủ thuốc làm giảm đáng kể tỉ lệ tái hẹp sau can thiệp hay siêu âm nội mạch (IVUS) trong lúc can thiệp... Tất cả những yếu tố trên giúp cho quá trình can thiệp trở nên an toàn và hiệu quả hơn.

Kháng đông: Tất cả các trường hợp chúng tôi đều sử dụng heparin 50 - 100UI/kg cân nặng sau khi đặt sheath và nhắc lại 1000UI mỗi 3 giờ trong thời gian can thiệp. Khi chuyển bệnh nhân sang săn sóc hậu phẫu dùng Plavix liều nạp 300mg, sau đó $75 \mathrm{gm} /$ ngày trong thời gian 3 tháng, thời gian tiếp theo sử dụng aspirin $81 \mathrm{mg} /$ ngày.
Brian G. DeRubertis và cs (2007), báo cáo kết quả can thiệp nội mạch 1000 chi trên 730 bệnh nhân tắc động mạch mạn tính chi dưới. Heparin được sử dụng 100UI/kg ngay sau khi đặt sheath, aspirin được sử dụng cho tất cả các trường hợp. Đối với bệnh nhân đặt stent hoặc cắt nội mạc thì dùng liều nạp Plavix 450mg tại đơn vị săn sóc hậu phẫu, sau đó $75 \mathrm{mg} /$ ngày liên tục trong 30 ngày [11].

\section{KẾT LUẬN}

Qua nghiên cứu 101 trường hợp tắc động mạch mạn tính dưới gối được điều trị bằng phương pháp can thiệp nội mạch, chúng tôi kết luận: Bệnh nhân chủ yếu lớn tuổi có nhiều yếu tố nguy cơ và bệnh kết hợp. Điều trị thường giai đoạn muộn, biểu hiện lâm sàng nặng với triệu chứng thiếu máu chi nghiêm trọng, tổn thương TASC II C, D chiếm đa số. Can thiệp nội mạch là phương pháp ít xâm lấn, kết quả sau 01 tháng, 12 tháng lần lượt là $86.2 \%$ và $53.7 \%$.

\section{TÀI LIỆU THAM KHẢO}

1. Andrew J. Feiring, Amy A. Wesolowski et al (2004), "Primary Stent-Supported Angioplasty for Treatment of Below-Knee Critical Limb Ischemia and Severe Claudication: Early and One-Year Outcomes", Journal of the American College of Cardiology, 44, 2307-2314.

2. Bruce H. Gray, Robert S. Dieter (2014), "SCAI Expert Consensus Statement for Infrapopliteal Arterial Intervention Appropriate Use", Catheterization and Cardiovascular Interventions, 84(4), 539-545.

3. Daniel Brandão, Armando Mansilha (2012), "Below the Knee Techniques: Now and Then", Angioplasty, Various Techniques and Challenges in Treatment of Congenital and Acquired Vascular Stenoses, InTech, Europe, Chap 3, 41-58. 
4. Francesco Liistro, Paolo Angioli et al (2013), "Drug-Eluting Balloon in Peripheral Intervention for Below the Knee Angioplasty Evaluation (DEBATE-BTK)", Interventional Cardiology, 128, 615-621.

5. Marco Manzi et al (2012), "Revascularization of Tibial and Foot Arteries: Below the Knee Angioplasty for Limb Salvage", Angioplasty, Various Techniques and Challenges in Treatment of Congenital and Acquired Vascular Stenoses, InTech, Europe, Chap 10, 210-232.

6. Michael R. Jaff C., William R. Hiatt (2015), "An Update on Methods for Revascularization and Expansion of the TASC Lesion Classification to Include Below-the-Knee Arteries: A Supplement to the Inter-Society Consensus for the Management of Peripheral Arterial Disease (TASC II)", Journal of Endovascular Therapy, 657-571.

7. Overhagen H. Van, Tsetis D. (2013), "CIRSE standards of practice guidelines : Below-the-knee Interventions ", Cardiovasc Intervent Radiol, 36, 302-311.
8. Joseph L. Mills, David G. Armstrong, et al (2014), "The Society for Vascular Surgery Lower Extremity Threatened Limb Classification System: risk stratification based on wound, ischemia, and foot infection (WIfI)", J Vasc Surg, 59(1), 220-234.

9. Sobieszczyk et al (2013), "Management of patients after endovascular interventions for peripheral artery disease", Circulation, 128(7), 749-757.

10. Steiner S, Schmidt A, Bausback Y, Bräunlich $S$, Ulrich $M$, Banning-Eichenseer U, Scheinert D.(2016): " Single-Center Experience With Lutonix Drug-Coated Balloons in Infrapopliteal Arteries " $\underline{\mathrm{J}}$ Endovasc Ther. 2016 Jun;23(3):417-23

11. DeRubertis B. G., Faries P. L., McKinsey J. F., Chaer R. A., Pierce M., Karwowski J., et al. (2007), "Shifting paradigms in the treatment of lower extremity vascular disease: a report of 1000 percutaneous interventions", Ann Surg, 246(3), 415-422; discussion 422-414 